\title{
Economic and Financial Consequences of Pandemics
}

\author{
Vahid Gholampour ${ }^{1}$ \\ ${ }^{1}$ Economics Department, Bucknell University, Pennsylvania, United States \\ Correspondence: Vahid Gholampour, Academic West Building, Bucknell University, Lewisburg, Pennsylvania, \\ 17837, United States. Tel: 1-570-577-1475. \\ Received: December 8, 2020 \\ Accepted: January 20, 2021 \\ Online Published: March 31, 2021 \\ doi:10.5430/rwe.v12n3p1 \\ URL: https://doi.org/10.5430/rwe.v12n3p1
}

\begin{abstract}
This paper studies the medium-term economic consequences of major pandemics since 1870. The paper compares the average path of economic and financial indicators after a pandemic with their long-term path. According to data, inflation is low over the decade that follows the end of a major pandemic. Investments drive the rebound in real GDP. Financial assets provide above-average real returns. Credit markets experience a boom while fiscal and monetary authorities cutback government expenditure and money supply after pandemics.
\end{abstract}

Keywords: pandemics, macroeconomics, asset prices, financial markets, housing

\section{Introduction}

Pandemics have significant effects on the economy and financial markets for many years. Previous studies document the sharp decline in economic activities during a pandemic (McKibbin \& Sidorenko 2006). An important consideration for policymakers and investors is the effect of pandemics on macroeconomic variables and capital markets during the years that follow a major pandemic. This paper sheds light on the short and medium-term effects of pandemics on macro and financial indicators. More specifically, the paper focuses on seven significant pandemics that occurred since 1870 and compares the path of macro variables after a pandemic with their long-run path. The paper studies the natural rate of several macro variables such as inflation, consumption, investments, and financial indicators such as the real returns of equity, soverign bond, and housing markets.

The results reveal several important patterns in the natural rate of macro variables after a major pandemic. First, inflation is consistently below its long-run average during the ten years that follow a pandemic. Second, financial assets provide above-average real returns. A break-down of financial assets shows that the real returns of both risky and safe assets are high after a pandemic. This finding is mainly driven by low inflation. Third, investments drive the increase in real GDP growth while the growth rate of government expenditure and money supply are below their long-term average. Finally, loans to businesses, households, and mortgage loans grow at above-average rates.

There are a number of papers that study the effect of a specific pandemic on one area of the world or the effect of pandemics on one specific macro variable. Karlsson, Martin, Therese Nilsson, \& Stefan Pichler (2014) study the economic impact of Spanish flu on Sweden. Keogh-Brown, Marcus Richard, Richard D. Smith, John W. Edmunds, \& Philippe Beutels (2010) use a multi-sector single country general equilibrium model to estimate the potential economic cost of a modern pandemic. Jordà, Òscar, Sanjay R. Singh, \& Alan M. Taylor (2020) examine the long-run consequences of pandemics on the real interest rate and wages. They use real interest rate data that goes back to the 14th century and show that their measure of the real natural rate of interest declines by almost 150 basis points twenty years after a pandemic. They also highlight the increase in wages, which they attribute to labor shortage after pandemics. While Jordà et al. (2020) study the long-term consequences of pandemics on the natural rate of interest, this paper focuses on the short and medium-term impacts of pandemics on various macroeconomic indicators and asset prices.

\section{Method}

\subsection{Data}

To study pandemics' effect on the economy and financial markets, one needs a time-series of asset prices and major macroeconomic indicators over a long time. This paper uses the macroeconomic history dataset from Jordà, Òscar, Katharina Knoll, Dmitry Kuvshinov, Moritz Schularick, \& Alan M. Taylor (2019). The dataset includes several 
macroeconomic variables and asset returns for 16 developed countries from 1870 to 2016 . The data frequency is annual, and the countries are United States, United Kingdom, Belgium, Denmark, France, Italy, Netherlands, Norway, Sweden, Switzerland, Canada, Japan, Finland, Portugal, Spain, and Australia (Note 1). The empirical section examines the response of the following variables to pandemics: Inflation measured as the year-over-year change in the consumer price index, changes in broad money supply, real change in government expenditure, real GDP growth, real consumption growth, real investment growth, real return of equity, housing, and government bond markets, real change in loans to households and businesses, and real change in mortgage loans.

This paper focuses on pandemics where more than one million people died. The number of deaths in the pandemics is adjusted to the world population in 2020. Table 1 shows the list of pandemics and their end year. The end year of the pandemics is from Cirillo and Taleb (2020).

Table 1. Major pandemic events with more than one million deaths

\begin{tabular}{ll}
\hline Pandemic & End Year \\
\hline Fourth cholera & 1875 \\
Russian flu & 1890 \\
Spanish flu & 1920 \\
Sixth cholera & 1923 \\
Encephalitis lethargica & 1926 \\
Asian flu & 1958 \\
Hong Kong flu & 1969 \\
\hline
\end{tabular}

\subsection{Empirical Methodology}

The goal is to study the path of macro variables and asset prices during the years that follow a major pandemic. To extract the slow-moving component of macro and financial indicators, I follow Jordà et al. (2020) and use a simple state-space model. The model consists of the following equations:

$$
\begin{aligned}
& f_{t}=f_{t}^{*}+e_{t} \\
& f_{t}^{*}=f_{t-1}^{*}+u_{t}
\end{aligned}
$$

The observed macro variable $f$ is the sum of an unobservable latent variable $f^{*}$ and noise. The second equation shows the dynamic process of the unobservable variable.

To measure the effect of pandemics on the economic and financial indicators, I compare the average path after a pandemic to the long-term path for various economic and financial variables. More specifically, I estimate $\beta_{h}^{p}$ in the following regressions,

$$
\Delta^{h} f_{t}^{*}=\alpha_{h}+\beta_{h}^{p} P_{t}+\beta_{h}^{w} W_{t}+\sum_{l=1}^{5} \gamma_{h}^{l} \Delta f_{t-l}^{*}++\varepsilon_{t, h}
$$

Where $\Delta^{h} f_{t}^{*}$ is the change in the natural rate of the economic variable of interest over $h$ years after $t$. The paper focuses on short to medium-term effects of pandemics and $h \in\{1,2, \ldots, 10\}$. $P_{t}$ is a pandemic dummy variable that is one for the end years of the pandemics and zero otherwise. To control for the effect of world wars, a dummy variable $W_{t}$ is included in the regressions. $W_{t}$ is one for all the years between 1914 and 1918 (first World War) and 1939 to 1945 (second World War). Five lags of one-year change in $f_{t}^{*}$ are also included in the regressions.

\section{Results}

This section provides the empirical findings in four subsections. The first subsection discusses the effect of pandemics on short and medium-term inflation. Since both inflationary and deflationary forces are present during a major health crisis, it is useful for various economic agents to know how price levels respond to a pandemic.

The second subsection studies real GDP growth and GDP components to learn about the main drivers of economic recovery after a pandemic. The last two subsections show the effect of pandemics on asset returns and credit markets. 


\subsection{Inflation}

Figure 1 shows the response of inflation to pandemics. The response is the coefficient of the pandemic dummy in the regressions shown in equation (3). Before discussing the empirical findings, a brief discussion on the interpretation of the coefficients is in order. Suppose the change in the natural rate of a given macro variable over $h$ years after a pandemic is not different from its change over other $h$-year periods. In that case, the coefficient of the dummy variable $\beta_{h}^{p}$ is zero.

Similarly, a positive (negative) coefficient indicates that, on average, changes in the natural rate of the macro variable are above (below) the long-term average. Figure 1 highlights below-average inflation rates during post-pandemic years. Inflation is consistently one full percentage point below its long-term average over the decade that follows a pandemic. Multiple factors could lead to low inflation after pandemics. A gradual change in consumer behavior could slow down the return of consumption growth to its long-term rate. Moreover, businesses might remain cautious and increase their investments at a slow rate after a pandemic. Low inflation could also be the result of cutbacks in government spending or contractionary monetary policies.

Figures 2 and 3 show that the growth rate of government spending and money supply are below their long-run average after pandemics. Slower growth in government spending and money supply could be partially responsible for low inflation during the post-pandemic years. The next section examines the effect of pandemics on real output and the components of GDP.

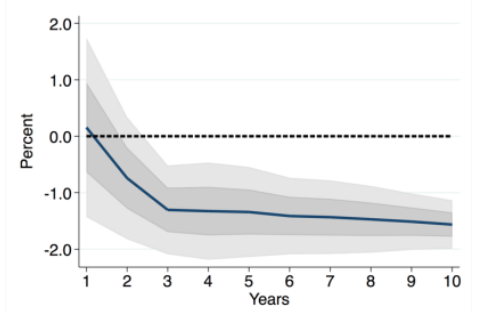

Figure 1. Response of inflation after pandemics

Note: Response calculated using equation (3). The shaded area shows one and two standard error bands around the point estimates.

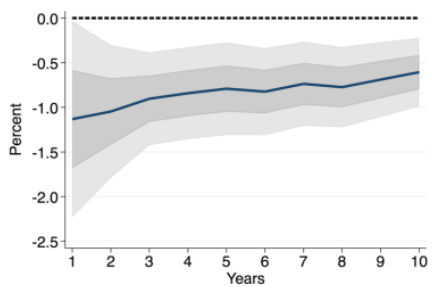

Figure 2. Change in real government expenditure after pandemics



Figure 3. Change in money supply after pandemics 


\subsection{Real Output}

Figure 4 highlights the above-average growth rate of real output during the years that follow the end of pandemics. This finding is not surprising as economic activities recover after a sharp decline caused by a significant health crisis.

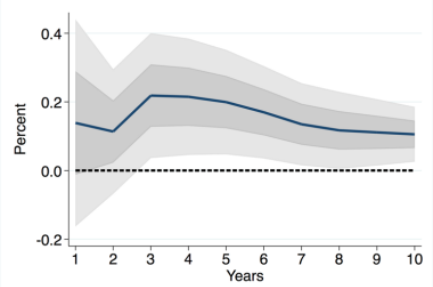

Figure 4. Response of real output after pandemics

Real consumption grows after pandemics, but the positive coefficients in Figure 5 are not statistically significant. The growth rate of investment is a full percentage point above its long-term rate after a pandemic, and the growth rate returns to its long-term average over ten years after the end of a pandemic. Figure 6 provides the average response of investments to pandemics. Given the muted response of real consumption and government spending, investment is the primary driver of output growth after a pandemic.

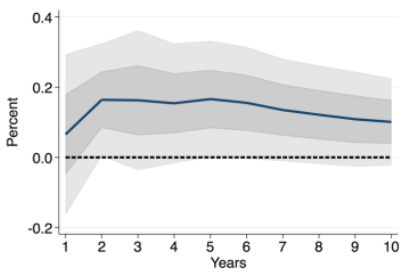

Figure 5. Response of real consumption after pandemics

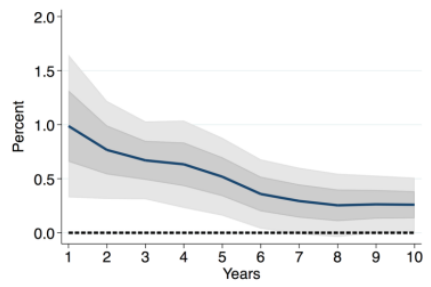

Figure 6. Response of investment after pandemics

\subsection{Asset Prices}

This section examines the effect of pandemics on short and medium-term real returns of various assets. Figure 7 shows the coefficients of the pandemic dummy $\beta_{h}^{p}$ in the regressions where the dependent variable is the natural rate of return on wealth over $h$ years. The total return on wealth is the weighted average of return on equity, housing, bonds, and bills. The average real return on wealth, shown in Figure 7, is consistently above its long-term average during the ten years that follow a pandemic. Figure 8 provides the response of risky and safe assets to pandemics. Return on risky assets is the weighted average of total return on equity and housing, and return on safe assets is the average return on bonds and bills. The figure shows that both risky and safe assets provide above-average returns during the post-pandemic years. We can further break down risky assets to identify the main drivers of asset returns. Figure 9 shows that both equity and housing markets provide above-average returns after pandemics. 


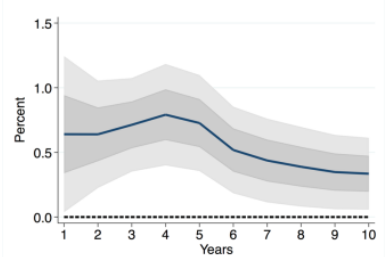

Figure 7. Real return on wealth after pandemics

Notes: Total Return on wealth is the weighted average of housing, equity, bonds, and bills.
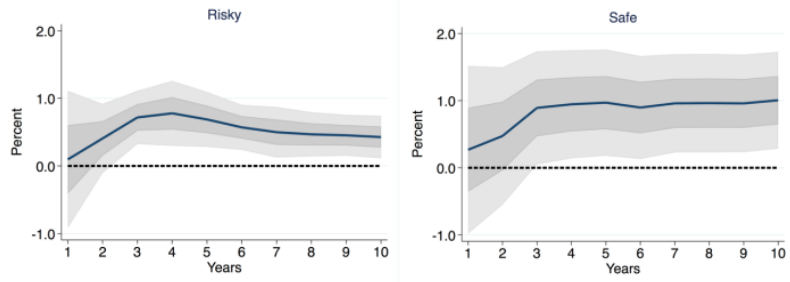

Figure 8. Real return on risky and safe assets after pandemics

Notes: The total return on risky assets is the weighted average of housing and equity. The total return on safe assets is an equally-weighted average of bonds and bills.
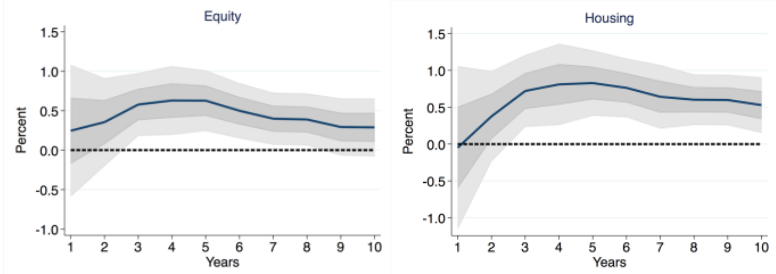

Figure 9. Real return of equity and housing markets after pandemics

\subsection{Credit Market}

Demand for credit is often seen as a sign of confidence and optimism about future growth. This section examines the growth rate of various types of loans after pandemics. Figure 10 shows that loans to households, loans to businesses, and mortgage loans grow at above-average rates during post-pandemic years. This finding is consistent with the earlier results. Loans to businesses grow during the same years that investments increase. Moreover, above-average growth in mortgage loans coincides with above-average increase in house prices. Figure 10 also indicates that loans to households grow during the post-pandemic years when real consumption remains steady. One possible explanation for this finding is that households invest the borrowed money in financial assets.
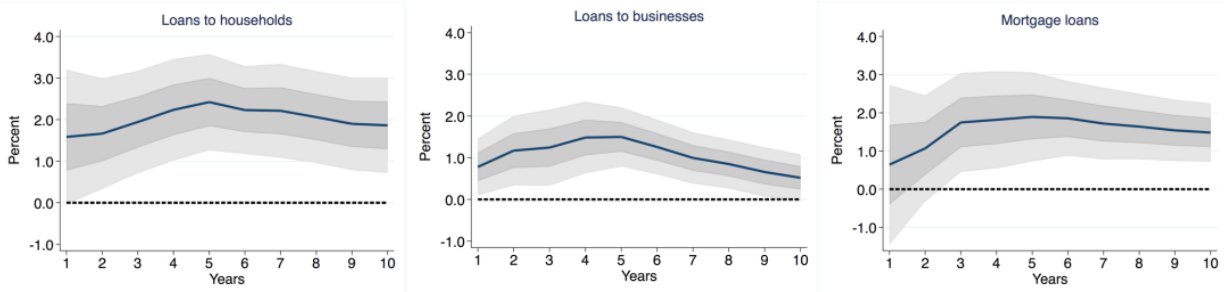

Figure 10. Real loan growth after pandemics 


\section{Conclusion}

The paper uses history as a guide to study the economic and financial consequences of pandemics. To that end, the paper compares the path after pandemics to the long-term path for various macroeconomic indicators and real asset returns. The paper focuses on significant pandemics with more than one million deaths between 1870 and 2016. The results are summarized as follows. Inflation is below its long-term average over ten years after pandemics. Investment is the primary driver of the rebound in real output. The real returns of safe and risky assets are above their long-term average during the post-pandemic years. Credit markets experience a boom after pandemics as loans to businesses, households, and mortgage loans grow at above-average rates.

The important question is what we can learn from the major pandemics in the past and how we could use our knowledge to develop public policies to combat the economic consequences of COVID-19. It was shown in section (3) that pandemics are associated with deflationary pressures that persist for many years. The result section also indicates that consumption recovers very slowly after a pandemic. Governments can fight deflation by implementing targeted stimulus programs to boost consumer confidence. Section 3.4 shows that loans to households grow at above-average rates after a pandemic. Since there is no evidence of higher consumption growth after pandemics, it is possible that households borrow to invest in financial assets. Widespread speculations in financial markets often threaten financial stability.

\section{References}

Keogh-Brown, M. R., Richard, D. S., John, W. E., \& Beutels, P. (2010). The macroeconomic impact of pandemic influenza: estimates from models of the United Kingdom, France, Belgium and The Netherlands. The European Journal of Health Economics, 11(6), 543-554. https://doi.org/10.1007/s10198-009-0210-1

Martin, K., Nilsson, T., \& Pichler, S. (2014). The impact of the 1918 Spanish flu epidemic on economic performance in Sweden: An investigation into the consequences of an extraordinary mortality shock. Journal of Health Economics, 36, 1-19. https://doi.org/10.1016/j.jhealeco.2014.03.005

McKibbin, W. J., \& Alexandra, S. (2006). Global macroeconomic consequences of pandemic influenza. Sydney, Australia: Lowy Institute for International Policy.

Òscar, J., Knoll, K., Kuvshinov, D., Schularick, M., \& Taylor, A. M. (2019). The rate of return on everything, 1870-2015. The Quarterly Journal of Economics, 134(3), 1225-1298. https://doi.org/10.1093/qje/qjz012

Òscar, J., Singh, S. R., \& Taylor, A. M. (2020). Longer-run economic consequences of pandemics. No. w26934. National Bureau of Economic Research.

Pasquale, C., \& Taleb, N. N. (2020). Tail risk of contagious diseases. Nature Physics, 1-8.

\section{Note}

Note 1. Germany is not included in this study because Germany's very high inflation during the mid-twentieth century could skew the results.

\section{Copyrights}

Copyright for this article is retained by the author(s), with first publication rights granted to the journal.

This is an open-access article distributed under the terms and conditions of the Creative Commons Attribution license (http://creativecommons.org/licenses/by/4.0/). 